\title{
AOR
}

Selected Papers of \#AolR2021:

The 22nd Annual Conference of the

Association of Internet Researchers

Virtual Event / 13-16 Oct 2021

\section{VIRTUAL LEARNING AFFORDANCES AND IDENTITY: A CASE STUDY}

Angela M. Cirucci

Rowan University

It is no surprise that universities' pandemic-induced move to virtual learning environments (VLEs) has provoked charged discussions of best practices including the "great camera debate" (e.g., Reed, 2020). While how to engage students online is a popular topic of study, largely left out are the ways in which the VLEs themselves have implications for student identity maintenance and, consequently, learning quality. This case study pairs a walkthrough analysis of two popular VLEs (Zoom and WebEx) with undergraduate responses $(n=250)$ to an open-ended survey to investigate how VLE affordances impact student identifications and quality of learning.

\section{Background}

While early social media like MySpace were exalted for inviting young adults to create bedroom-like personalized spaces (e.g., Hodkinson, 2017), VLEs actually place professors and classmates into students' rooms and homes. Indeed, social media apps allow students to craft identities and edit before posting; but VLEs, although borrowing some social media functionalities, place students in new, live contexts.

Studies have shown that collaboration and communication lead to student satisfaction and academic achievement (Abuhassna et al., 2020; Almarzooq et al., 2020). Additionally, social presence (with both professors and classmates) is positively correlated with learning quality. However, professors find these types of relationships difficult when students will not, or cannot, turn on their cameras during synchronous courses (Andel et al., 2020; Reich et al., 2020).

Affordances of digital spaces refer to the relationships that exist between tool and user (e.g., Nagy \& Neff, 2015) and impact how identities are shared and shaped (Duguay, 2016). Previous studies have found that social media spaces privilege certain identities over others, often marginalizing groups (e.g., Cirucci, 2017). Against this backdrop, this study explores how students experience VLEs and suggests ways to offer more inclusive learning environments online. 


\section{Method}

First, a walkthrough analysis (Light et al., 2018) was conducted on two popular VLEsZoom and WebEx. Second, an open-ended survey was advertised through a university's student listserv. The survey focused on topics including VLE preference, camera habits, "camera readiness," background choices, and personalization tools used.

\section{Findings}

Three preliminary themes are explicated below. Additional themes will be included once data analysis is complete.

\section{User Friendly}

Although Zoom and WebEx offer similar features, Zoom's end-user interface, both in organization and design, feels like a traditional social media app. Indeed, most participants explained that they prefer Zoom because it is "user-friendly:"

P74: I prefer zoom. I think zoom is the most user-friendly platform.

This appification of desktop programs includes using larger buttons and forgoing traditional window dropdown menus. Zoom's structure allows for cleaner design, but also hides options. WebEx's desktop application, on the other hand, looks more like a traditional desktop window and feels more professional. Although participants largely prefer Zoom because it reminds them of being within social media apps with which they are already comfortable, students may be feeling a false sense of security, not realizing that they generally do not feel comfortable turning on their cameras because, ultimately, their live video feed cannot be edited like an Instagram post or TikTok video.

Few participants had ever heard of, let alone employed, the many identity management functions Zoom offers-adding a profile picture, changing their display name, using appearance "touch up," or switching to a virtual background. However, this is not surprising - the tools are not advertised in the main window and require diving into less user-friendly (and less app-like) settings options.

\section{Location Appearance}

Even though most participants do not use virtual backgrounds, many noted that they feel self-conscious about their classmates and professors seeing their physical location. Some explained they worry about a mess or distractions in the background. But others, often participants whose family incomes are below $\$ 50,000$, noted they fear others will judge their home. 
P13: I definitely feel self-conscious because I feel that a lot of people are judging me I see people in their own homes and they are talking about how they are in their personal office or they are outside near their pool or outside on their porch and patio and I do not have that luxury

A few participants also cited privacy concerns, noting that their bedrooms and homes are supposed to be private places that professors and classmates should not be privy to, contrary to any direct link between contemporary social media and bedrooms:

P102: I don't like that my professors and peers can see my bed as my room is supposed to be a private place where I can relax.

The only exception is students who live in dorms. Multiple participants, across all demographics, noted that they have no problem turning on their cameras because they assume a dorm room is neutral territory:

P41: [My] background is just a...dorm and maybe students have the same housing setting as me.

\section{Physical Appearance}

Multiple students explained that they do not turn on their cameras because they are self-conscious about their appearance. This was especially true of BIPOC who identify as women. These participants noted that they are concerned with their physical appearance, feeling like people are always staring at them during class. These women also included more elaborate "camera ready" procedures that they completed before logging on, even if they rarely turn on their cameras.

P3: I get a bit self conscious about my appearance. Especially for the 8 ams because I wake up and I do my morning routine of brushing my hair and teeth etc but I still personally think I look very unattractive. This is mostly because of my dark circles they are genetic :/

These fears are clearly tied to the ways in which society polices BIPOC (particularly those who identify as women) bodies (e.g., Hattery \& Smith, 2021). Interestingly, BIPOC women are also less likely to use other communication tools like embedded chat and emoji reactions, perhaps signaling that once a student feels uncomfortable, they are unlikely to be immersed at all.

\section{Final Thoughts}

Undergraduates are still struggling to navigate the changes that VLEs bring. But these changes are felt more acutely by groups who are already marginalized. Because Zoom mimics popular social media app tropes, students lean toward these normalized spaces, but this does not mean they benefit from them. Just as with popular social media apps, space for identity performance privileges normative narratives and makes it difficult for users to traverse options that may provide a more inclusive learning space. Few 
students, no matter their identifications, employ identity tools, in line with social media trends-users who identify with more privileged identities feel the space is already made for them while users who identify with less privileged identities are accustomed to forcing themselves into what is considered "normal" and thus also do not seek out identity personalization options (e.g., Cirucci, 2017).

Professors and universities alike should offer training sessions not only for VLE functionality but also for identity maintenance, guiding students through largely hidden personalization options. VLEs should work less to mimic social media apps and more to imitate physical learning spaces, providing inclusive experiences that benefit diverse learners. Finally, professors should not force students to turn on cameras or provide narrow paths to participating. Instead, students should be allowed to show attention and progress in numerous ways including using emojis reactions and chat functions.

\section{References}

Abuhassna, H., Al-Rahmi, W. M., Yahya, N., Zakaria, M. A. Z. M., Kosnin, A. B. M., \& Darwish, M. (2020). Development of a new model on utilizing online learning platforms to improve students' academic achievements and satisfaction. International Journal of Educational Technology in Higher Education, 17(1). https://doi.org/10.1186/s41239-02000216-z

Almarzooq, Z. I., Lopes, M., \& Kochar, A. (2020). Virtual learning during the COVID-19 pandemic: a disruptive technology in graduate medical education. Journal of the American College of Cardiology, 75(20), 4. https://doi.org/https://doi.org/10.1016/j.jacc.2020.04.015

Andel, S. A., de Vreede, T., Spector, P. E., Padmanabhan, B., Singh, V. K., \& De Vreede, G.-J. (2020). Do social features help in video-centric online learning platforms? A social presence perspective. Computers in Human Behavior, 113, 106505.

Cirucci, A. M. (2017). Normative interfaces: Affordances, gender, and race in Facebook. Social Media + Society, 3(2), 1-10.

Hattery, A. J., \& Smith, E. (2021). Policing black bodies: How black lives are surveilled and how to work for change. Rowman \& Littlefield Publishers.

Hodkinson, P. (2017). Bedrooms and beyond: Youth, identity and privacy on social network sites. New Media \& Society, 19(2), 272-288.

Light, B., Burgess, J., \& Duguay, S. (2018). The walkthrough method: An approach to the study of apps. New Media \& Society, 20(3), 881-900.

Nagy, P., \& Neff, G. (2015). Imagined affordance: Reconstructing a keyword for communication theory. Social Media+ Society, 1(2), 2056305115603385. 
Reed, M. (2020). Should showing faces be mandatory? Inside Higher Ed.

Reich, J., Buttimer, C. J., Coleman, D., Colwell, R. D., Faruqi, F., \& Larke, L. R. (2020). What's lost, what's left, what's next: Lessons learned from the lived experiences of teachers during the 2020 novel coronavirus pandemic. MIT Teaching Systems. https://edarxiv.org/8exp9 